\title{
Cuidados especiais na área de cirurgia e traumatologia bucomaxilofacial frente à COVID-19
}

Special care in the area of buccomaxillofacial surgery and trauma in face of COVID-19

Atención especial en el área de cirugía buccomaxilofacial y traumatología en comparación con COVID-19

Matheus Francisco Barros RODRIGUES ${ }^{1}$

Layla Louise de Amorim ROCHA ${ }^{\mathbf{1}}$

Rimsky Coelho Lopes da ROCHA ${ }^{2}$

Rodrigo da Franca ACIOLY ${ }^{3}$

Daniel do Carmo CARVALHO 3

Dennis Dinelly de SOUZA ${ }^{3}$

Cristofe Coelho Lopes da ROCHA ${ }^{4}$

${ }^{1}$ Curso de Odontologia, Faculdade Cathedral, 69307-053 Boa Vista - RR, Brasil

${ }^{2}$ Centro de Pesquisas Odontológicas, São Leopoldo Mandic, Boa Vista 69305-455, Brasil

${ }^{3}$ Departamento de Cirurgia e Traumatologia Bucomaxilofacial, Hospital Geral de Roraima, 69305-455 Boa Vista - RR, Brasil

${ }^{4}$ Departamento infraestrutura, Instituto Federal, 69303-340 Boa Vista - RR, Brasil

\section{Resumo}

A organização mundial de saúde definiu o surto do novo coronavírus como uma emergência de saúde pública de interesse internacional. A média de idade da ocorrência da doença ocasionada pelo vírus está na faixa de 49 a 59 anos. Os sintomas da infecção da COVID-19 incluem febre, tosse e doença respiratória aguda. Muitos procedimentos bucomaxilofaciais hospitalares produzem aerossóis e gotículas contaminados por sangue, bactérias e vírus. O objetivo desse estudo é reunir recomendações de órgãos de saúde e artigos científicos para orientação do cirurgião quanto aos procedimentos de atendimento e tratamentos em cirurgia bucomaxilofacial. A finalidade é prevenir a transmissão da Covid-19 durante o tratamento de paciente em situação de urgência e emergência. A metodologia utilizou as orientações do Colégio Brasileiro de Cirurgia e Traumatologia Buco-maxilo-facial, além de recomendações e dados epidemiológicos de órgãos de saúde nacionais e internacionais e artigos científicos publicados. Os cirurgiões bucomaxilofaciais, por natureza correm alto risco de exposição a doenças infecciosas. O surgimento da COVID-19 impôs novos desafios quanto a compreensão da transmissão do vírus por meio de gotículas de saliva e aerossóis.

Descritores: Infecções por Coronavirus; Emergências; Procedimentos Cirúrgicos Bucais.

\section{Abstract}

The world health organization has defined the outbreak of the new coronavirus as a public health emergency of international interest. The average age of the occurrence of the disease caused by the virus is in the range of 49 to 59 years. Symptoms of COVID-19 infection include fever, cough and acute respiratory disease. Many hospital oral-maxillofacial procedures produce aerosols and droplets contaminated by blood, bacteria and viruses. The objective of this study is to gather recommendations from health agencies and scientific articles to guide the surgeon as to the procedures for care and treatments in oral and maxillofacial surgery. The purpose is to prevent the transmission of Covid-19 during the treatment of patients in urgent and emergency situations. The methodology used the guidelines of the Brazilian College of Oral and Maxillofacial Surgery and Traumatology, in addition to recommendations and epidemiological data from national and international health agencies and published scientific articles. Oral and maxillofacial surgeons, by nature, are at high risk of exposure to infectious diseases. The emergence of COVID-19 posed new challenges in understanding the transmission of the virus through saliva droplets and aerosols.

Descriptors: Coronavirus Infections; Emergencies; Oral Surgical Procedures.

\section{Resumen}

La organización mundial de la salud ha definido el brote del nuevo coronavirus como un emergencia de salud pública de interés internacional. La edad promedio de aparición de la enfermedad causada por el virus está en el rango de 49 a 59 años. Los síntomas de la infección por COVID-19 incluyen fiebre, tos y enfermedad respiratoria aguda. Muchos procedimientos hospitalarios oral-maxilofaciales producen aerosoles y gotas contaminadas con sangre, bacterias y virus. El objetivo de este estudio es recopilar recomendaciones de agencias de salud y artículos científicos para guiar al cirujano en cuanto a los procedimientos para el cuidado y los tratamientos en cirugía oral y maxilofacial. El propósito es prevenir la transmisión de Covid-19 durante el tratamiento de pacientes en situaciones urgentes y de emergencia. La metodología utilizó las pautas del Colegio Brasileño de Cirugía y Traumatología Oral y Maxilofacial, además de recomendaciones y datos epidemiológicos de agencias de salud nacionales e internacionales y artículos científicos publicados. Los cirujanos orales y maxilofaciales, por naturaleza, tienen un alto riesgo de exposición a enfermedades infecciosas. La aparición de COVID-19 planteó nuevos desafíos para comprender la transmisión del virus a través de gotas de saliva y aerosoles.

Descriptores: Infecciones por Coronavirus; Urgencias Médicas; Procedimientos Quirúrgicos Orales.

\section{INTRODUÇÃO}

Em dezembro de 2019 diversos casos de pneumonia de origem desconhecida foram relatados em Wuhan na China ${ }^{1-3}$. A origem mais provável do surto seria um vírus transmitido por morcegos e hospedeiros intermediários, chamados pangolins ${ }^{3,4}$. Entretanto, algumas características do vírus ainda são desconhecidas. ${ }^{5}$. Um mês depois os cientistas identificaram um novo tipo de coronavírus ${ }^{1}$.

O coronavírus foi inicialmente denominado 2019-nCoV e em seguida foi oficialmente definido como SARS-CoV-2. A doença originada pelo novo coronavírus foi denominada de COVID-19, onde CO significa corona, VI para vírus e D para doença6 e foi reconhecida em 34 países $^{4,6}$.
Em 31 de janeiro de 2020, a organização mundial de saúde - OMS (do inglês World Health Organization - $\mathrm{WHO}^{1}$ ) definiu o surto do novo coronavírus como uma emergência de saúde pública de interesse internacional ${ }^{1,2,4,5,7}$. A disseminação da doença se espalhou para diversas regiões do mundo chegando na América Latina em 25 de fevereiro de 2020, quando o Ministério da Saúde do Brasil confirmou o primeiro caso.

Segundo Ministério da Saúde do Brasil, até o dia 08 de maio de 2020 foram confirmados 145.328

\footnotetext{
A OMS é sediada em Genebra na Suíça, entrou em vigor em 7 de abril de 1948 data que é comemorado o dia mundial da saúde. Disponível em: https://www.who.int/home
} 
casos de pacientes acometidos pelo COVID-19 e 9.897 óbitos confirmados, como pode ser visto no Gráfico 1.

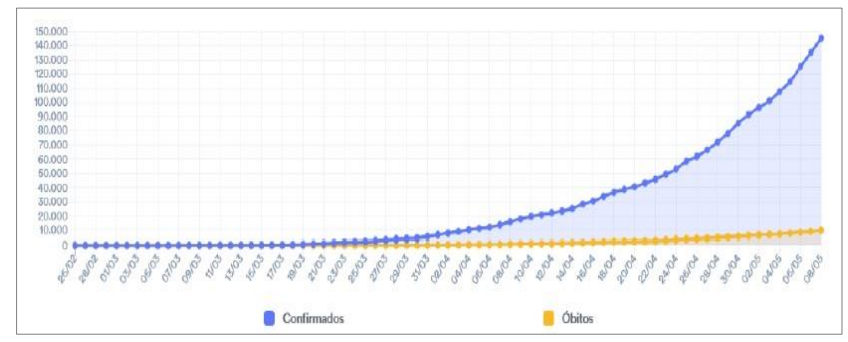

Gráfico 1: Casos e óbitos confirmados do COVID-19 no Brasil.

Fonte: Boletim epidemiológico do centro de operações de emergências de saúde pública, 08 de maio de 2020, Secretaria de Vigilância em Saúde/Ministério da Saúde. Disponível en https://portalarquivos.saude.gov.br/images/pdf/2020/May/09/2020-05-06-BEE15-Boletim-do-COE.pd

A maioria dos casos apresentou a doença com sintomas relativamente leve e de acordo com os dados da Comissão Nacional de Saúde da China (Do Inglês National Health Commission of the $\mathrm{PRC}^{2}$ ), a proporção de casos graves na China foi de cerca de $15 \%$ a $25 \%$, . Os sintomas da infecção por COVID19 incluem febre, tosse e doença respiratória aguda, em casos graves evoluem para pneumonia, insuficiência renal resultando até na morte do infectado $^{5,6}$. A idade avançada e a existência de comorbidades subjacentes (diabetes, hipertensão e doenças vasculares) estão associadas ao pior prognóstico4. O período de incubação foi estimado entre 5 a 6 dias em média podendo durar até 14 dias. A duração é comumente adotada para observação médica durante a quarentena ${ }^{4}$. Durante o período, a transmissão pode ocorrer antes que os sintomas apareçam ${ }^{5}$.

Acredita-se que a transmissão interpessoal ocorra principalmente por gotículas respiratórias e contato direto com pessoas infectadas ${ }^{1-4}$. Além disso, pode haver risco de transmissão orofecal ${ }^{4}$. Recentemente, o corona vírus foi encontrado na saliva de pacientes infectados ${ }^{5,9}$. Estudos reforçaram ainda mais a possibilidade de transmissão por meio de gotículas orais, em virtude da grande quantidade de RNA de SARS-CoV encontrada ${ }^{10}$. É importante que os profissionais de saúde bucal estejam atentos para evitar a disseminação ${ }^{5}$, pois o vírus pode sobreviver nas mãos, objetos e superfícies que foram infectados pela saliva por até nove dias ${ }^{7}$.

Muitos procedimentos bucomaxilofaciais hospitalares produzem aerossóis e gotículas contaminados por sangue, bactérias e vírus ${ }^{1}$. A inalação de partículas aerossóis produzidos em paciente com a COVID-19 representa alto risco de infecção cruzada entre cirurgiões e pacientes ${ }^{2,4,5}$. O objetivo desse estudo é reunir recomendações de órgãos de saúde e artigos científicos para auxiliar o cirurgião quanto aos procedimentos em cirurgia e

\footnotetext{
2 A Comissão Nacional de Saúde da China é responsável por elaborar leis e regulamentos para políticas nacionais de saúde na República da China. Disponível em: http://en.nhc.gov.cn/
}

traumatologia bucomaxilofacial (CTBMF). A finalidade é diminuir a transmissão da Covid-19 durante o atendimento de paciente em situação de urgência e emergência.

MATERIAL E MÉTODO

Recomendações do Colégio Brasileiro de Cirurgia e Traumatologia Bucomaxilofacial, Ministério da Saúde do Brasil, Organização Mundial da Saúde, Agência Nacional de Vigilância Sanitária $\left(\right.$ ANVISA $^{3}$ ), Conselho Federal de Odontologia do Brasil (CFO) e Comissão Nacional de Saúde da China foram utilizadas para consubstanciar a contribuição desse estudo em questões relacionadas às precauções nos procedimentos CTBMF frente a transmissão da COVID-19. Foram realizadas pesquisas nas bases de dados Scielo, Pubmed, Google Acadêmico, Portal de Periódicos da Capes e Servidores de Pré-Impressão a fim de levantar informações sobre o histórico do vírus a fim de reconhecer suas características e rotas de transmissão. A abordagem desse trabalho está relacionada a medidas de precaução e cuidados com a finalidade de equacionar questões relacionadas a transmissão da COVID-19 por meio de gotículas de salivas e aerossóis em ambiente hospitalar e ambulatorial no âmbito da cirurgia bucomaxilofacial em procedimentos de urgência e emergência.

\section{RESULTADOS E DISCUSSÃO}

- Contaminação por saliva e aerossol em cirurgia bucomaxilofacial

Foi verificado que superfícies contaminadas são uma via de transmissão de vários patógenos nosocomiais. Quando uma pessoa tosse, espirra, ri ou fala são expelidas gotículas grandes de salivas com tamanho superior a $5 \mu \mathrm{m}$ de diâmetro e gotículas de aerossóis pequenas que são menores ou iguais a $5 \mu \mathrm{m}$ de diâmetro ${ }^{2,3}$, como pode ser visto na Figura 1.

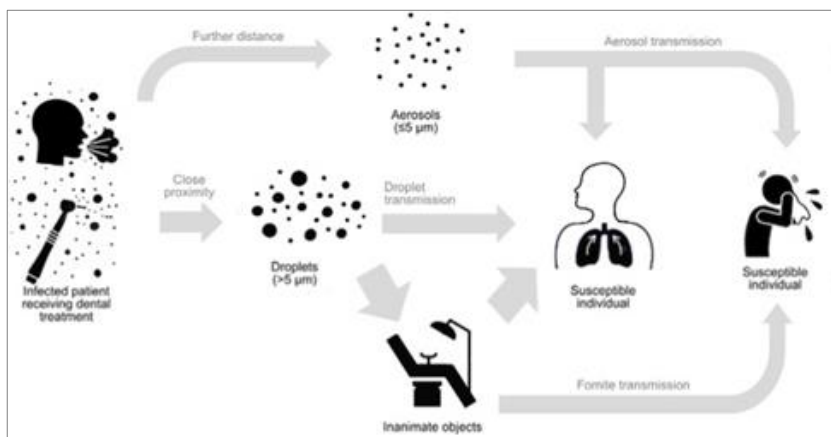

Figura 1: Distintas rotas de transmissão do COVID-19 (Fonte: GE et. al. ${ }^{2}$ )

As partículas podem seguir diferentes rotas de transmissão por meio de gotículas, aerossóis ou mesmo superfícies contaminadas durante um 
procedimento cirúrgico. As gotículas grandes alcançam menores distâncias por conta da força gravitacional que faz com que as gotículos logo caiam (Figura 1). Portanto a contaminação por essas gotículas requer maior proximidade entre o indivíduo infectado e o suscetível ${ }^{2}$. As gotículas aerossóis pequenas tem baixa velocidade de sedimentação e podem viajar por maiores distâncias conforme Figura 1 , antes de adentrar no trato respiratório ou contaminar objetos ${ }^{2}$. Algumas medidas podem ser adotadas com a intenção de diminuir os riscos de contaminação, tais como: aspiração contínua de saliva e uso de colutórios com intuito de diminuir a carga viral. Para pacientes em unidade e terapia intensiva (UTI) sugere-se uso de peróxido de hidrogênio de $05 \%$ a $1 \%$ ou povidona a $0,2 \%{ }^{11}$.

Durante um procedimento de cirurgia bucomaxilofacial utilizando alta velocidade com peça de mão e irrigação abundante, ocorre a produção de aerossóis combinados com fluidos corporais da cavidade bucal (saliva e sangue). O procedimento aumenta ainda mais a capacidade de transmissão para indivíduos suscetíveis, conforme Figura 1 na seta transmissão por aerossóis ${ }^{2}$. Frequentemente, atividades bucomaxilofaciais são desenvolvidas em ambientes hospitalares em caráter de urgência e emergência. Os procedimentos adotados durante o tratamento requerem medidas de precauções. Algumas recomendações de precaução foram indicadas em função do cenário atual da COVID-19.

\section{- Precauções em cirurgias bucomaxilofaciais}

Durante o atendimento hospitalar algumas ocorrências são consideradas de caráter emergencial quando há risco de morte do paciente, são elas: hemorragia, celulites ou infecções bacterianas difusas com presença de edema localizado intra ou extraoral, além de potencial risco de comprometimento da via aérea do paciente e traumatismo envolvendo os ossos da face com potencial comprometimento da via aérea do paciente ${ }^{12}$. As ocorrências de urgência fazem parte do cotidiano do cirurgião bucomaxilofacial e, embora não haja comprometimento eminente da vida, algumas precauções especiais devem ser observadas a fim de diminuir o risco de transmissão de infecções. Durante a prática bucomaxilofacial, algumas diretrizes técnicas são seguidas como precauções padrões do controle de infecções. Em função do surto epidemiólogico da COVID-19 algumas precauções especiais foram incrementadas como forma de prevenção ${ }^{2}$.

A Tabela 1 foi construída com base nas recomendações da ANVISA em associação com o Conselho Federal de Odontologia (CFO), Colégio Brasileiro de Cirurgia e Traumatologia Bucomaxilofacial e Associação de Medicina Dentária (AMIB) em parceria com o CFO. Nela estão descritas situações de urgência e emergência em pacientes com ou sem suspeita para COVID-19, além de pacientes confirmados. A coluna "Precauções Especiais" descreve condutas a serem adotadas pelo cirurgião e sua equipe diante de cada situação.

\begin{tabular}{l|l} 
Tabela 1. Situações e precauções especiais para tratamento em CTBMF \\
\hline Situação do paciente para COVID-19/ tratamento & \multicolumn{1}{|c}{ Precauções especiais } \\
\hline Sem suspeita/Eletivo & $\begin{array}{l}\text { Suspensão temporária de } \\
\text { procedimentos eletivos11. Deve- se } \\
\text { postergar o tratamento diante da } \\
\text { situação }{ }^{12,13}\end{array}$ \\
\hline Com suspeita/Eletivo & $\begin{array}{l}\text { O tratamento deve ser postergado e } \\
\text { o paciente com suspeita deve ser } \\
\text { orientado a fazer isolamento } \\
\text { domiciliar imediatamente e } \\
\text { procurar serviço de saúde somente } \\
\text { em caso de agravamento dos } \\
\text { sintomas }{ }^{11}\end{array}$ \\
\hline Sem suspeita/Urgência e Emergência & $\begin{array}{l}\text { O tratamento deve ser realizado } \\
\text { com precaução padrão com uso de } \\
\text { equipamentos de proteção } \\
\text { individual (EPI) e adicionais para } \\
\text { toda a equipe }\end{array}$ \\
\hline Com suspeita/Urgência e Emergência & $\begin{array}{l}\text { O tratamento deve ser realizado } \\
\text { com precaução (padrão e } \\
\text { adicionais) para toda a equipe }\end{array}$ \\
\hline Positivo/Urgência e Emergência & $\begin{array}{l}\text { Requer tratamento imediato em } \\
\text { cuidados hospitalares e/ou clínicas } \\
\text { onde há todos os EPIs } \\
\text { apropriados }\end{array}$ \\
\hline
\end{tabular}

Durante a execução dos procedimentos de urgência e emergência em ambiente hospitalar devese utilizar os EPIs como gorro, óculos de proteção, protetor facial, avental impermeável, luvas de procedimento e máscara N95/PFF2 ou equivalente ${ }^{12}$. Todavia, é importante pontuar que alguns exames e procedimentos exigem maiores precauções por parte do cirurgião bucomaxilofacial e sua equipe. A justificativa é diminuir o risco de contaminação por meio de secreções bucais e respiratórias em pacientes suspeitos ou diagnosticados com COVID- $19^{12}$.

Um exemplo a ser citado é o exame de oroscopia cuja recomendação é ser solicitado apenas a pedido médico e em caráter de urgência e emergência. Radiografias devem ser preferencialmente extraorais, evitando o contato com fluidos corporais ${ }^{12}$. Medidas intraoperatórias que limitam a geração de aerossóis devem ser adotadas; portanto, durante a intubação a equipe deve ficar do lado de fora da sala por até 20 minutos após o procedimento, preferivelmente realizado pelo membro mais experiente da equipe ${ }^{13}$. Há estratégias para reduzir a geração de gotículas e aerossóis em práticas de cirurgia bucomaxilofaciais: ao realizar uma extração dentária simples, o cirurgião deve posicionar o paciente em decúbito dorsal para evitar o contato direto com a via respiratória do paciente ${ }^{2}$.

\section{CONSIDERAÇÕES FINAIS}

No exercício da sua atividade profissional os cirurgiões bucomaxilofaciais correm alto risco de exposição a doenças infecciosas. $\mathrm{O}$ surgimento da COVID-19 impôs novos desafios quanto à compreensão da transmissão do vírus, por meio de gotículas de saliva e aerossóis. Além das precauções já padronizadas, a implementação de precauções especiais pode impedir a transmissão da doença por 
portadores do novo coronavírus. As precauções especiais auxiliam no controle da propagação do COVID-19, permitindo uma análise prévia de procedimentos de risco em casos que é necessário a urgência e emergência.

\section{REFERÊNCIAS}

1. Guo H, Zhou Y, Liu X, Tan J. The impact of the COVID-19 epidemic on the utilization of emergency dental services. J Dent Sci. 2020;10.1016/j.jds.2020.02.002.

2. Ge ZY, Yang LM, Xia JJ, Fu XH, Zhang YZ. Possible aerosol transmission of COVID-19 and special precautions in dentistry. J Zhejiang Univ Sci B. 2020;21(5):361-68.

3. Rodrigues MFB, Rocha LLDA, Acioly RDF, Souza DDD, Carvalho DDC, Rocha RCLD, Rocha CCLD. Special precautions in oral and maxillofacial surgeries regarding COVID-19 transmission. Preprints 2020, 2020050135 (doi: 10.20944/preprints202005.0135.v1).

4. Meng L, Hua F, Bian Z. Coronavirus Disease 2019 (COVID-19): Emerging and Future Challenges for Dental and Oral Medicine. J Dent Res. 2020;99(5):481-87.

5. Sabino-Silva R, Jardim ACG, Siqueira WL. Coronavirus COVID-19 impacts to dentistry and potential salivary diagnosis. Clin Oral Investig. 2020;24(4):1619-21.

6. Tuñas ITC, Silva ET, Santiago SBS, Maia KD, Silva-Júnior GO. Doença pelo Coronavírus 2019 (COVID-19): Uma abordagem preventiva para Odontologia. Rev Bras Odontol. 2020;77(1):1-6.

7. Spagnuolo G, De Vito D, Rengo S, Tatullo M. COVID-19 Outbreak: An Overview on Dentistry. Int $\mathrm{J}$ Environ Res Public Health. 2020;17(6):2094.

8. Yang Y, Lu Q, Liu M, Wang Y, Zhang A, Jalali N et al. Epidemiological and clinical features of the 2019 novel coronavirus outbreak in China. medRxiv 2020. doi: https://doi.org/ 10.1101/2020.02.10.20021675.

9. To KKW, Tsang OTY, Leung WS, Tam AR, Wu TC, Lung DC et al. Temporal profiles of viral load in posterior oropharyngeal saliva samples and serum antibody responses during infection by SARS-CoV-2: an observational cohort study. Lancet Infect Dis. 2020;20(5):565-74.

10. Wang WK, Chen SY, Liu IJ, Chen YC, Chen HL, Yang CF et al. Detection of SARS-associated coronavirus in throat wash and saliva in early diagnosis. Emerg Infect Dis. 2004;10(7):1213-19.

11. Associação de Medicina Intensiva Brasileira. Conselho Federal de Odontologgia. Recomendações A, para atendimento odontológico COVID C. Comitê de Odontologia AMIB/CFO de enfrentamento ao COVID-19
Departamento de Odontologia AMIB-1 Atualização 25/03/2020. São Paulo: AMIB; 2020.

12. Brasil. Agência Nacional de Vigilância Sanitária. Nota técnica GVIMS/GGTES/ANVISA $\mathrm{N}^{\circ}$ 04/2020. Orientações para Serviços de Saúde: Medidas de Prevenção e Controle que devem ser adotadas durante a assistência aos casos suspeitos ou confirmados de infecção pelo novo Coronavírus (SARS-COV-2). Brasília: ANVISA; 2020.

13. Colégio Brasileiro de Cirurgia e Traumatologia Bucomaxilofacial. COVID-19 - Guia de Práticas em CTBMF. Disponível em: https://www.bucomaxilo.org.br/site/noticiasdetalh es.php?cod=344\&amp;q=COVID19\%2B $\% 20 \% 2$ BGuia\%2Bde\%2BPr\%C3\%A1ticas\%2Bem\%2BC TBMF\&amp;bsc=ativar. Acesso em: 07 de abr. de 2020.

\section{CONFLITO DE INTERESSES}

Os autores declaram não haver conflitos de interesse.

\section{AUTOR PARA CORRESPONDÊNCIA}

Matheus Francisco Barros Rodrigues
Curso de Odontologia, Faculdade Cathedral
69307-053 Boa Vista - RR, Brasil
e-mail: matheusfbr18@ @mail.com

Submetido em 11/05/2020 Aceito em 03/07/2020 